NBER WORKING PAPER SERIES

\title{
RETHINKING HOW WE SCORE CAPITAL GAINS TAX REFORM
}

\author{
Natasha Sarin \\ Lawrence H. Summers \\ Owen M. Zidar \\ Eric Zwick \\ Working Paper 28362 \\ http://www.nber.org/papers/w28362
NATIONAL BUREAU OF ECONOMIC RESEARCH
1050 Massachusetts Avenue
Cambridge, MA 02138
January 2021

We thank Coly Elhai for outstanding research assistance. We received helpful comments from Tim Dowd, Robert McClelland, Rich Prisinzano, Jim Poterba, and others who wish to remain anonymous. These acknowledgments should not be interpreted as implying that these individuals are in agreement with this paper's conclusions. This work is supported by National Science Foundation under Grant Number 1752431. We declare that we have no relevant or material financial interests that relate to the research described in this paper other than owning some assets which have unrealized accrued capital gains. The views expressed

herein are those of the authors and do not necessarily reflect the views of the National Bureau of Economic Research.

NBER working papers are circulated for discussion and comment purposes. They have not been peer-reviewed or been subject to the review by the NBER Board of Directors that accompanies official NBER publications.

(C) 2021 by Natasha Sarin, Lawrence H. Summers, Owen M. Zidar, and Eric Zwick. All rights reserved. Short sections of text, not to exceed two paragraphs, may be quoted without explicit permission provided that full credit, including (C) notice, is given to the source. 
Rethinking How We Score Capital Gains Tax Reform

Natasha Sarin, Lawrence H. Summers, Owen M. Zidar, and Eric Zwick

NBER Working Paper No. 28362

January 2021

JEL No. H0,H2,H3

\begin{abstract}
$\underline{\text { ABSTRACT }}$
We argue the revenue potential from increasing tax rates on capital gains may be substantially greater than previously understood. First, many prior studies focus primarily on short-run taxpayer responses, and so miss revenue from gains that are deferred when rates change. Second, the composition of capital gains has shifted in recent years, such that the share of gains that are highly elastic to the tax rate has likely declined. Third, focusing on capital gains tax collection may understate fiscal spillovers from decreasing the preferential tax treatment for capital gains. Fourth, additional base-broadening reforms, like eliminating stepped-up basis and making charitable giving a realization event, will decrease the elasticity of the tax base to rate changes. Overall, we do not think the prevailing assumption of many in the scorekeeping community - that raising rates to top ordinary income levels would raise little revenue-is warranted. A crude calculation illustrates that raising capital gains rates to ordinary income levels could raise $\$ 1$ trillion more revenue over a decade than other estimates suggest. Given the magnitudes at stake, scorekeeping procedures employed in evaluating capital gains should be made more transparent and be the subject of external professional debate and review.
\end{abstract}

Natasha Sarin

University of Pennsylvania

Carey Law

Silverman 139

3501 Sansom Street

Philadelphia, PA 19104

nsarin@law.upenn.edu

Lawrence H. Summers

Harvard Kennedy School of Government

79 JFK Street

Cambridge, MA 02138

and NBER

lhs@harvard.edu
Owen M. Zidar

Department of Economics \&

School of International and Public Affairs

Princeton University

237 Julis Romo Rabinowitz Building

Princeton, NJ 08544

and NBER

ozidar@princeton.edu

Eric Zwick

Booth School of Business

University of Chicago

5807 South Woodlawn Avenue

Chicago, IL 60637

and NBER

ezwick@chicagobooth.edu 


\section{Introduction}

Capital gains taxes are a perennial issue in tax reform debates. Some maintain that preferential rates on capital gains encourage entrepreneurship and capital formation. Others question whether these benefits are sufficiently large to outweigh the equity and fiscal costs of lower rates. While the direct equity costs of lower rates are clear - the wealthiest one percent account for two-thirds of capital gains realizations in the 2019 Survey of Consumer Finances - the fiscal costs are more uncertain.

The Joint Committee on Taxation (JCT) estimates these costs. In the parlance of policymakers, the JCT is the official "scorekeeper" who decides how tax legislation "scores" if implemented. The prevailing wisdom among some in the scorekeeping community (e.g., Tax Policy Center, Tax Foundation, Penn Wharton Budget Model) has been that the revenue-maximizing capital gains rate is around 30 percent, such that setting a rate too far above this level could actually reduce the total amount of revenue collected. ${ }^{1}$ This "Laffer rate" is well below both current top marginal tax rates on other income and top rates currently under debate. The rationale for a low Laffer rate is that the static revenue gains expected from a high rate will fail to materialize because the dynamic response of taxpayers dramatically shrinks the tax base.

Accounting for the difference between static and dynamic scores is clearly important. For example, the official score attached to changes in the top income tax rate is perhaps 12 percent lower than the static score, because some taxpayers will choose to work less, or hire tax planners to help avoid taxes more. ${ }^{2}$ But in the capital gains context, dynamic effects are often assumed to exceed 100 percent, because rate hikes lock-in realizations that would have otherwise occurred. Deploying this assumption, increases in the capital gains tax rate have previously been estimated to lose revenue, and decreases, to raise revenue. ${ }^{3}$

It seems natural that the dynamic effects in the case of capital gains are more pronounced than for other policies: Retiming a capital gain realization in an investor's stock portfolio is easier than changing investment strategy for executives seeking to avoid a corporate tax increase, or reducing labor supply for workers when income tax rates rise. But we suspect that these behavioral effects are overstated, resulting in a potentially severe underestimate of the revenue at play from capital gains tax increases.

The current "realization elasticity" used by JCT and others in the scorekeeping community is approximately -0.7, based both on historical scores (Joint Committee on Taxation, 1990) and more recent academic research (Dowd, McClelland and Muthitacharoen, 2015). If tax rates increased by 100\%, crude application of this elasticity implies that only $53 \%(=1-(0.7 \times 0.67))$ of gains will be realized. ${ }^{4}$ In concrete terms, roughly $\$ 1$ trillion of annual realizations would shrink to around $\$ 500$ billion. This assumed $\$ 500$ billion response is large enough that raising capital gains rates to ordinary income levels could be scored as raising no new revenue.

\footnotetext{
${ }^{1}$ For example, McClelland provides a short discussion of revenue-maximizing rates, noting that "the Tax Policy Center uses estimates that imply that the revenue from taxing long-term capital gains is maximized when the top rate is set to be about 28 percent" and the Treasury Department, and JCT appear to use similar estimates. https://www.taxpolicycenter.org/taxvox/ new-study-suggests-congress-could-raise-money-increasing-capital-gains-tax-rates-47-percent

${ }^{2}$ See Saez, Slemrod and Giertz (2012), which uses an elasticity of taxable income of -0.2.

${ }^{3}$ Indeed, in the 1990s, a long line of academic and policy work was focused on whether decreasing the capital gains tax rate was likely to pay for itself (Gravelle, 1991; Auten and Cordes, 1991).

${ }^{4}$ Note that $0.67=.20 / .30$, which is the rate change from $20 \%$ to $40 \%$ divided by the mid-point. This stylized example abstracts from the $3.8 \%$ net investment income tax and other tax considerations.
} 
This style of calculation neglects a material offsetting factor: medium-term retiming of realizations would offset lost revenues in the short-term. Suppose that doubling capital gains rates from $20 \%$ to $40 \%$ causes realizations to occur half as often: instead of realizing gains every year, individuals realize gains every two years. If assets grow at 10\% annually, then in the low-tax regime, $\$ 100$ of assets yield realizations of $\$ 10$ in year 1 and $\$ 10.80$ in year 2 (after paying two dollars of tax in year 1). In the high-tax regime, $\$ 100$ of assets yield realizations of $\$ 0$ in year 1 and $\$ 21$ in year 2. Despite the appearance in year 1 of a large elasticity of realizations in response to the tax increase, total revenues over both years increase from $\$ 4.16$ in the low-tax regime to $\$ 8.40$ in the high-tax regime. In this simple example without other behavioral responses, the short-run revenue score is zero and the medium-run revenue score is double the baseline. Clearly, the latter revenue score is more relevant for policy purposes.

It is not clear to what extent these dynamic factors are incorporated in current scorekeeping methods, or if instead the current approach predicts that annual realizations would permanently fall. Given scarce public information about official scorekeeping methods, we are not in a position to evaluate how these methods account for such medium-run behavior. It is also unclear how much additional base-broadening reforms, like stepped-up basis and making charitable giving a realization event, would affect estimates of lost tax collection due to indefinite deferrals. This ambiguity also impairs the ability of new research to contribute to improving our understanding of dynamic taxpayer responses.

Beyond the issue of deferred gains, we highlight three additional considerations that suggest conventional elasticities may be overstated. First, the composition of capital gains has shifted in recent years, such that the share of capital gains that are highly elastic to the tax rate has fallen. Today, nearly half of capital gains accrue through passthrough and mutual fund distributions outside of the direct control of taxpayers. If half of capital gains are not sensitive to the tax environment, then for $e=-0.7$ to be the right average elasticity across all gains, the elasticity for the other half of gains would be $e=-1.4$. And even in the extreme case that the timeable realizations were to shrink to zero, a large stock of gains that will be taxed regularly at higher rates would remain. Moreover, the appropriate elasticity for scoring big tax increases should put more weight on the elasticity of the less timeable portion since it will account for more of the remaining tax base. It is unclear whether scorekeeping models account for compositional changes and dynamic weights.

Second, revenue estimates may understate the substitution between capital gains and other forms of income. Third, the uncertainty about how scorekeepers incorporate dynamic effects into various capital gains reform proposals complicates apples-to-apples evaluation of alternatives. These issues are all deserving of further study. Overall, we do not think the prevailing assumption by many in the scorekeeping community - that raising rates to top ordinary income levels would raise little revenue - is warranted by a reasonable reading of the evidence.

We conclude with crude estimates of the wide range in revenue potential from raising capital gains rates to the top ordinary income levels under different elasticity assumptions. Applying the conventional elasticity $e=-0.7$ leads to the conclusion that this substantial rate increase would raise less than $\$ 150$ billion in revenue. In stark contrast, using an elasticity that incorporates medium-term dynamics suggests that raising rates to the top ordinary income level could raise more than $\$ 1$ trillion over a decade. Put differently, $e=-0.7$ implies 
that once capital gains rates reach around 30 percent, the additional increase to top ordinary rates loses, rather than raises, revenue. Our preferred estimates suggest the opposite. Pairing rate increases with the elimination of loopholes that erode the capital gains tax base-like stepped-up basis and the tax preference for charitable gifts of appreciated assets - produces larger revenue estimates. We provide a simple calculation that abstracts from many important details. Our point is not to offer an official score, but instead to illustrate the magnitude of potential revenue and how sensitive capital gains revenue estimates are to various assumptions. We suspect that making scorekeeping procedures more transparent and the subject of external professional debate and review will lead to an upward revision in the estimated revenue potential from substantially increasing capital gains tax rates.

\section{Short-Run Deferral Increases Medium-Run Realizations}

\subsection{Longer estimation window produces smaller elasticity estimates}

A long estimation window is necessary to measure the dynamic response and revenue effects of capital gains tax changes. The reason is that gains deferred when taxes rise may not, in fact, be deferred indefinitely. Auerbach (1989) provides a helpful model that we describe in the Appendix. In the model, rate changes may induce less frequent asset turnover, but at least some portion of gains deferred will face a tax burden eventually. And when deferred realizations do occur, the gains will be larger, as they will accrue over many years, offsetting transient losses from delays in realization. Working through the long-run dynamic equilibrium properties of whatever elasticity is estimated is quite important. In general, increasing the frequency of realizations means that the average realization will be smaller, and decreasing the frequency of realizations means that when they do occur, they will be larger. The impact on the size of the taxable gain works against this baseline effect and is missed by short-term elasticity estimates.

There is a long line of empirical research on the responsiveness of capital gains realizations to rate changes, relying on different methodologies for estimating taxpayer response, different sample periods, and different rate changes from which to derive estimates (Dowd and Richards, 2021). Importantly, varying realization elasticities across studies often reflect the horizon over which taxpayer responses are estimated. Due largely to data limitations, much of the literature has estimated a short-run elasticity by studying responses within a short window before and after tax changes. If researchers and professional scorekeepers adopt the short-run elasticity as the relevant statistic for revenue estimation, they implicitly presume that realizations that are deferred when rates rise will never take place.

Consider two recent contributions. Dowd, McClelland and Muthitacharoen (2015) use micro panel data from the 2000s to estimate a permanent elasticity of -.72, based on taxpayer responses from the two years surrounding tax changes. A limitation of this approach is that it misses out on realizations that are deferred when rates change, but occur eventually, just outside of the years immediately surrounding tax changes. Consistent with this idea, Dowd, McClelland and Muthitacharoen (2015) find that their estimates are exclusively driven by intensive margin effects (i.e., the size of a realized gain), indicating this approach may miss medium-run timing 
responses that are more likely to appear as extensive margin effects (i.e., the presence of a realized gain).

Agersnap and Zidar (2020), in contrast, capture realizations that occur at the state-level within ten years of a tax change (Figure 1). Consistent with the deferred realization hypothesis, they arrive at an estimate of the behavioral effect of capital gains tax hikes that is much lower than existing estimates (between -.3 and -.5), and consequently an estimate of the revenue-maximizing rate that is much higher, around 38 to 47 percent. There are issues with this ten-year horizon as well. On the one hand, estimates are less precise in later years since other shocks occur during such a lengthy estimation window. On the other, even this more expansive estimation window misses realizations deferred when rates change that occur eventually, just outside of the ten-year horizon.

Figure 1: Evolution of realization responses: Elasticity estimates by horizon from Agersnap and Zidar (2020)

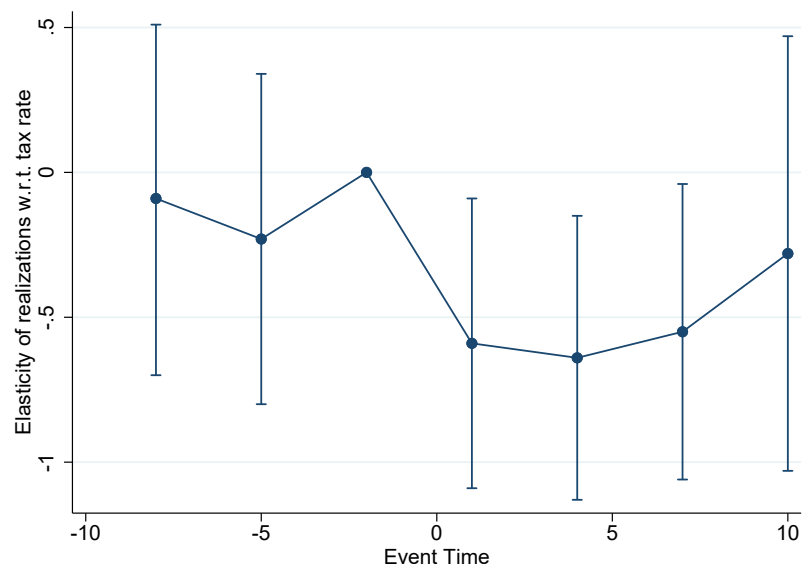

Notes: This figure plots tax rate elasticities within 3-year bins defined relative to the year of a tax change. For instance, the rightmost point indicates that the realizations elasticity to a tax change 9 and 11 years previous is -0.28 . This figure is constructed by converting the policy-relevant elasticity $\left(\varepsilon_{C G}-\varepsilon_{N}\right)$ series from Figure 3(c) of Agersnap and Zidar (2020) to a taxrate elasticity. We use a conversion factor of $\frac{-0.22}{1-0.22}$ so that the result is an elasticity at a tax rate of 22 percent.

A critique of both Dowd, McClelland and Muthitacharoen (2015) and Agersnap and Zidar (2020) is that their identification relies on relatively small state-level tax changes. An alternative approach would be to use the time series of large federal changes to examine dynamics around larger reforms. The only comparable historical episodes in the U.S. are in the 1970s, when capital gains rates rose following the Tax Reform Act of 1969 to 49 percent, before being cut to 29 percent by the end of the decade. However, the lack of a comparison group and the existence of confounding shocks makes clear how difficult it is to identify the permanent tax-induced component of this change from the federal time series.

Figure 2 plots aggregate realizations and capital gains tax rates and reveals clear issues with extrapolation from the federal time series. First, the time series show clear anticipatory and transient taxpayer timing, providing more evidence of why elasticities based on just a few years of data can be misleading. Second, the base of capital gains is procylical, so it is hard to disentangle changes in realizations from unrelated marketinduced changes in tax collections. The 1970s featured capital gains tax hikes, decreases in capital gains tax collection as a share of GDP, and poor market performance-all of which reversed in the 1980s. Figure 
2(b) shows a sharp decline in C-corporation equity wealth as a share of GDP in the 1970s, which confounds inferences about the tax elasticity based solely on time-series fluctuations in rates and realized gains. Looking to state-level changes is thus valuable, as it is a broader sample that allows for separating tax-induced changes from general macroeconomic trends.

Figure 2: Evolution of Net Capital Gains and C-Corporation Equity Wealth

(a) Capital gains

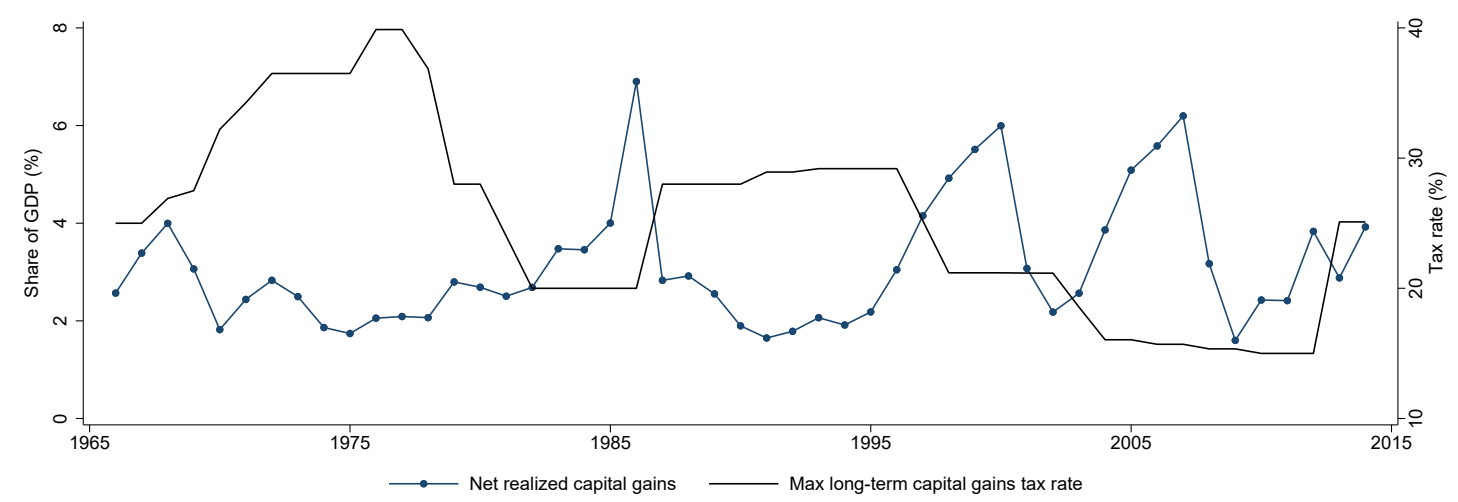

(b) C-Corporation equity wealth

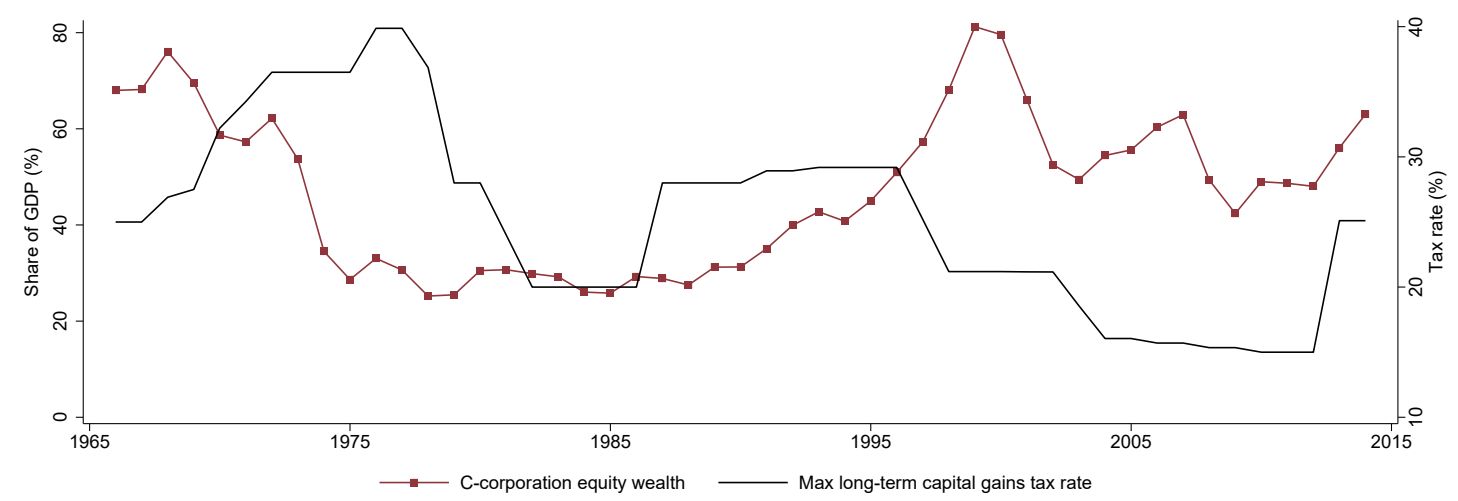

Notes: These graphs plot net realized capital gains, C-corporation equity wealth, and the maximum long-term capital gains tax rates between 1960 and 2014 as a share of GDP. Data on capital gains and C-corporation wealth from Smith, Zidar and Zwick (2020). Data on tax rates from the U.S. Treasury (https://www.treasury.gov/resource-center/tax-policy/ tax-analysis/Documents/Taxes-Paid-on-Capital-Gains-for-Returns-with-Positive-Net-Capital-Gains.pdf) and the Tax Foundation (https://taxfoundation.org/federal-capital-gains-tax-collections-1954-2009/). GDP data from the World Bank (https://data. worldbank.org/indicator/NY.GDP.MKTP.CD).

\subsection{Some portion of deferred gains are eventually realized}

Overall, many empirical estimates in the capital gains literature are lacking because without lengthening the window beyond a year or two, one cannot measure relevant medium- and long-term responses. If taxpayers respond to increases in capital gains rates by realizing gains less frequently — but not deferring indefinitelythen these longer-run responses would suggest the impact of rate changes on capital gains tax collection is more temporary than previously believed.

If this were the case, one would expect to observe a few patterns in the data when rates increase. First, 
the duration that taxpayers hold their gains before realizing would rise. Second, the ratio of sales price to basis would be higher: In the Auerbach framework discussed in the Appendix, $\delta$ represents the share of realizations that occur annually. If a capital gains change affects $\delta$, the share of annual realizations falls, but when realizations occur, gains relative to purchase basis are higher.

The IRS SOCA (Sales of Capital Assets) study provides some suggestive evidence on these patterns. The SOCA panel data includes the sales price, basis, gain or loss, and the purchase and sales date for capital gains transactions for a representative sample of taxpayers. This data is at the federal level and only for certain years between 1997-2012. ${ }^{5}$ As such, there is just one federal tax change during the time covered by these data, the 2003 reform, which reduced the top rate from $20 \%$ to $15 \%$. This is one of many areas where more recent and comprehensive IRS data would be invaluable: Regular SOCA panels would enable better inference about the extent to which realization behavior has changed over time.

Figure 3 shows that, for all transactions and corporate stock transactions specifically, duration decreases in lockstep with the rate change. In other words, the share of assets held for more than ten years drops when the rate falls, and the ratio of sales price to basis falls (Figure 4). It is worth noting that this evidence is purely suggestive - these two periods are distinct and differences in macroeconomic conditions may well be driving the results. ${ }^{6}$ But the figures are consistent with the notion that at least some of the changes induced by capital gains reforms have to do with the timing of gains, and not just the decision of whether or not to realize. Models that assume only the latter channel is operating will miss out on the revenue potential of rate changes.

Figure 3: Holding Length by Asset Class

(a) Held less than 5 years

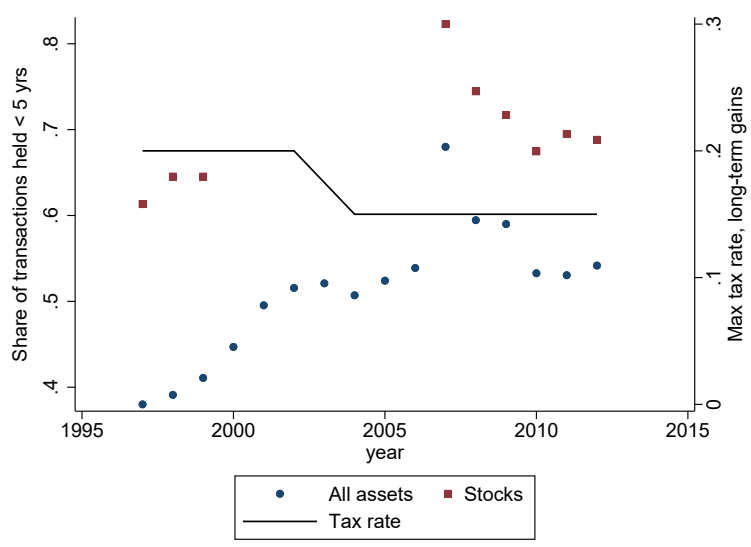

(b) Held 10 years or more

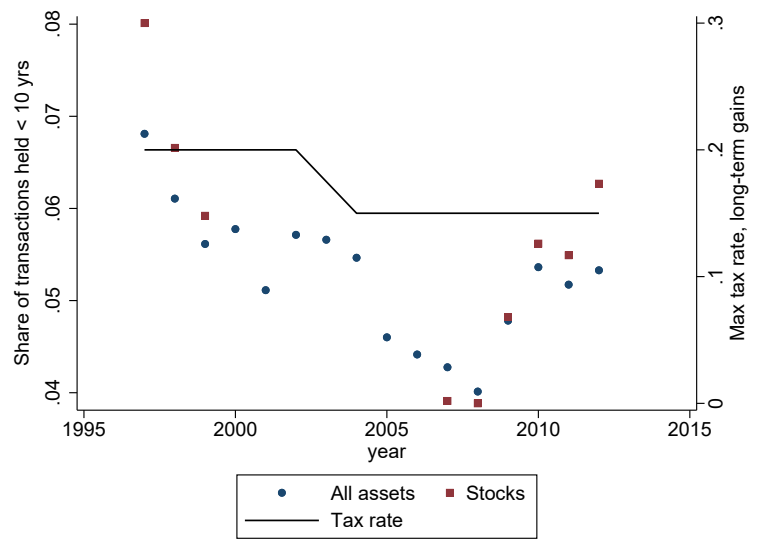

Notes: These graphs plot the average share of capital gains realizations that are held for less than five years and for more than 10 years. For reference, we also plot the maximum federal long-term capital gains tax rate. Data from the IRS SOCA.

\footnotetext{
${ }^{5}$ There is also a 1985 SOCA study but there are no study files for other years in the 1980s and early 1990s.

${ }^{6}$ Indeed, the share of assets held for long periods is mechanically tied to recent market movements: when the stock of capital gains rises significantly in a year, the share of total gains that have been held for long periods drops.
} 
Figure 4: Price-to-Basis Ratio by Asset Class

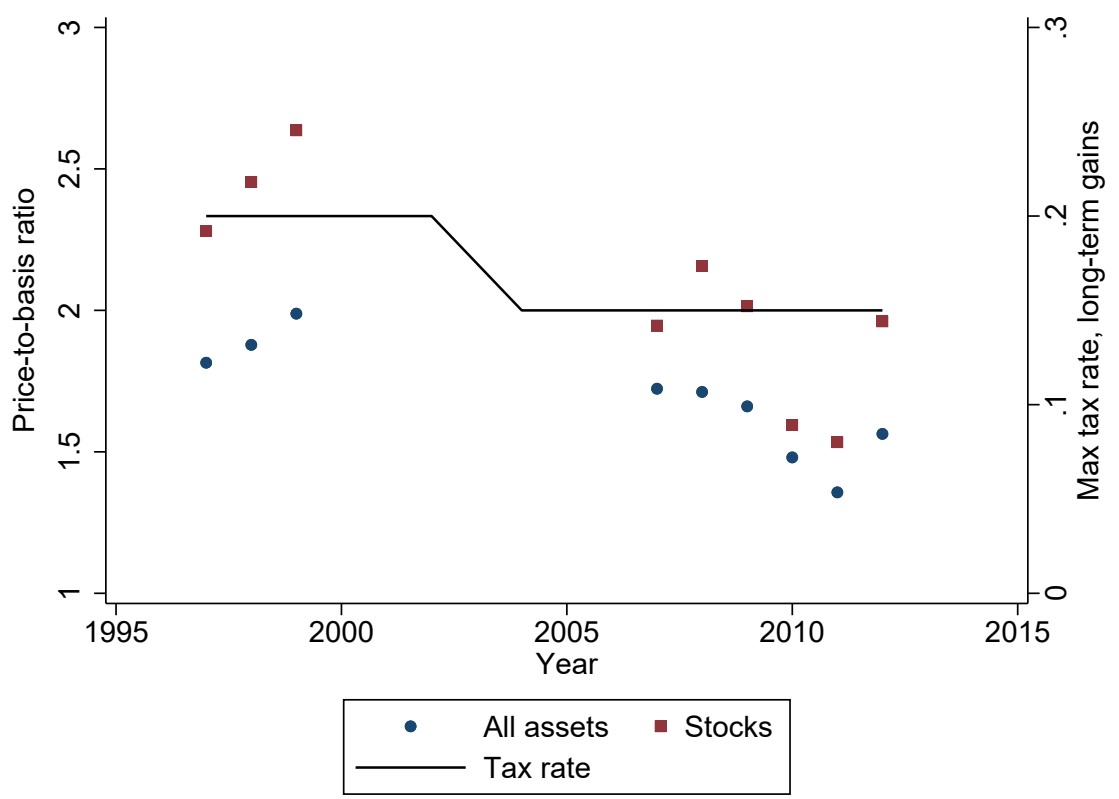

Notes: This graph plots the ratio of sales price to basis for long-term gain realizations of all assets and for stocks only. For reference, we also plot the maximum federal long-term capital gains tax rate. Data from the IRS SOCA.

\subsection{Tax law changes make it unlikely that taxpayers can defer gains indefinitely}

An early theoretical paper by Stiglitz (1983) suggests that the avoidance opportunities for capital gains taxes are so rampant that the existence of a tax would have no impact on individual consumption, because the tax can be avoided entirely through a range of techniques like the use of derivatives.

Whether the assumptions that underlie this model were ever realistic is debatable. A long line of literature documents that most trading activity is inconsistent with tax-motivated realizations, which pushes against the idea that investors are so active in their tax avoidance strategies. ${ }^{7}$ Further, to the extent that these opportunities did exist, they are more limited today than they were in the 1980s.

For example, Section 1259 of the tax code was adopted in 1997 and required that a constructive sale of property held by a taxpayer be treated for the purposes of recognizing gain and establishing a holding period as if she had sold the property in question for its fair market value. Section 1259 leaves some room for forward contracts designed for the holder to defer tax liability for a period (typically three to five years) while receiving cash today. But recent legal precedent makes clear that there are limits to this strategy that make it infeasible for gains periods to be rolled over indefinitely. ${ }^{8}$ Thus, this strategy offers only a temporary salve to inevitable capital gains tax liability.

For those at the top of the wealth distribution, diversification, rather than consumption, needs likely drive

\footnotetext{
${ }^{7}$ See, for example, Odean $(1998,1999)$ and Barber and Odean (2000). In more recent work looking at bunching behavior around capital gains tax thresholds, Dowd and McClelland (2019) find that many taxpayers appear to pursue "distinctly inferior tax minimization [strategies]" when selling assets (p.347).

${ }^{8}$ See, for example, Estate of Andrew J. McKelvey V. Commissioner, No. 17-2554 (2d Cir. 2018).
} 
some realization choices. But for taxpayers who are looking to consume out of their gains, it is plausible that they could borrow against shares that have accumulated in value, thus deferring capital gains liability. However, potential borrowers are likely to face sizable marginal calls because of the volatility of their underlying shares. They thus need to have sufficient liquidity on hand, which makes consumption without realization challenging.

Outside of the wealthiest who actively choose not to diversify (e.g., founders with large equity stakes), it seems unlikely that rate changes could conceivably lock-in accrued gains until death. More quantitative work is needed to try and measure the behavior of and share of gains held by taxpayers across the wealth distribution.

\section{A Rising Share of Capital Gains Cannot Be Easily Retimed}

Relative to the 1990s, the portion of assets where accumulated capital gains could conceivably be deferred - and thus untaxed - has declined. The prototypical example of a capital gain is a share of corporate stock. An individual who bought a share of Amazon when it IPO-ed at $\$ 18$ could sell that share today, and pay taxes on more than $\$ 3,100$ of appreciation. Or, if she does not face consumption needs during her lifetime, she could defer the gains indefinitely and bequest the share of stock to her heirs, at which point the basis will adjust and wipe out any tax liabilities for appreciated gains during her lifetime.

Stock transactions are among the most elastic form of capital gains, since the taxpayer can proactively decide whether or not to realize. But, as Figure 5 shows, the share of capital gains that stock transactions represent has fallen substantially over the course of the last several decades, while more inelastic gains are growing in import: between 1997 and 2012, the share of long-term gains that involved corporate stock transactions fell from $41.2 \%$ to $26.9 \%$.

The largest corresponding growth is in passthrough gains or losses, which rose from just $22.6 \%$ of long-term gains to $37.7 \%$. Pass-through gains refer to distributed gains from pass-through entities owned by taxpayers. This category includes the growth of "carried interest" compensation to general partners of hedge funds, venture capital, and private equity firms. Partnership agreements typically require funds to be returned within ten to twelve years of the initial commitment. Investors in these structures cannot time realization decisions around favorable tax environments, as their participation is limited, nor can they typically defer their gains indefinitely like stockholders. Instead, they receive - and pay taxes on - gains when the general partners exit underlying investments. Moreover, many of the limited partners in these funds are non-taxable, such that the decision to exit an investment is likely to be less responsive to capital gains tax changes.

Considering this shift in composition suggests that conventional elasticities are likely overstated. The most recent data available from the IRS reveal that nearly half of capital gains accrue from passthrough and mutual fund distributions. It is hard to know what share of non-personal capital gains are timeable around tax changes (e.g., corporate stock held by partnerships) and what share are inelastic (e.g., carried interest, which itself represents around $10 \%$ of annual capital gains in recent years (Smith, Zidar and Zwick, 2020)). It seems plausible that between $30 \%$ to $50 \%$ of capital gains are not easily timeable in response to tax changes. If $50 \%$ of gains are untimeable, then for $e=-0.7$ to be the right average elasticity across all gains, then the remaining 


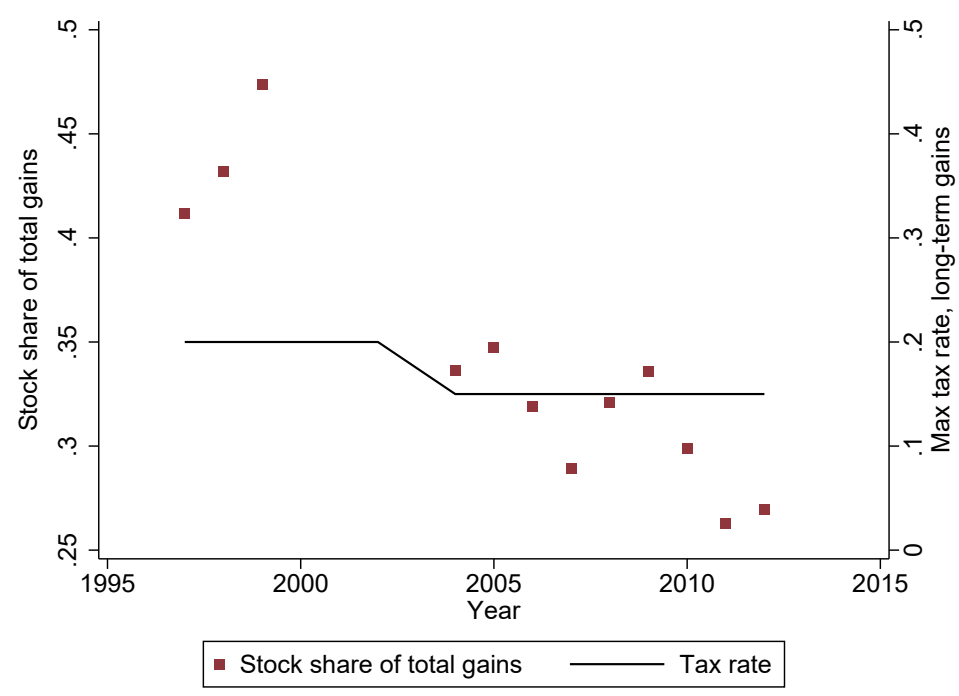

Notes: Points represent the corporate stock share of total capital gains realized in a given year. These are plotted alongside the maximum federal long-term capital gains rate. Data from the IRS SOCA.

$50 \%$ of timeable capital gains that are elastic to the tax rate should have an elasticity of close to -1.4.

Said another way, if $50 \%$ of capital gains are not sensitive to the tax environment, then no matter how large the "timeable" elasticity is, doubling rates to top ordinary income levels will still raise substantial revenues. Even if the timeable realizations shrink to zero, there remains a large stock of gains that will be taxed regularly at new, higher rates. Moreover, the appropriate elasticity for bigger changes should put more weight on the elasticity of the less timeable portion. The elasticities used by scorekeepers are averages across different asset types. But the weights are not static: when there is a substantial change in the tax environment, the weights of the different asset classes that comprise the capital gains tax base shift, and so too does the elasticity of the overall tax base. It is no accident that when capital gains tax rates are low (or, when taxpayers predict that rates may rise in the near future), a large share of realizations are in easily-timeable equities. This dynamism appears missing from existing revenue estimates.

Work by Dowd, McClelland and Muthitacharoen (2015) confirms that different types of assets exhibit different realization elasticities, finding for example that pass-through distributions exhibit a higher sensitivity to rate changes than other types of assets, while mutual fund distributions exhibit a much lower sensitivity. However, their data runs from 1999 through 2008, so may not reflect the current composition of gains. In addition, they find the elasticity of directly-owned capital gains varies over different time periods and is lower in recent years. Further research incorporating the growth of carried interest and the quantitative importance of different types of gains and their varied elasticities would be useful for improving assessments of the revenue potential of capital gains tax reform. 


\section{Realization Responses Generate Fiscal Spillovers}

\subsection{Capital gains tax changes affect tax collections beyond realization responses}

Elasticity estimates from the literature tend to focus on the narrow question of how the capital gains tax base evolves in response to rate changes, but this approach offers an incomplete answer to the question of total revenue effects. Perhaps scorekeepers are already modeling such spillovers, but we are unaware of the approach, the assumed magnitudes, and the empirical basis for these assumptions.

Consider a few examples of how changes in the capital gains tax might affect other tax bases. First, incentives to mischaracterize labor income and profits as capital gains to take advantage of lower tax rates can also affect revenues (Smith, Yagan, Zidar and Zwick, 2019). The existence of preferential tax treatment encourages avoidance in the form of misclassification of wage income for fund managers through the carried interest loophole, discussed above. Similarly, the tax code favors employee stock options, which, when held for long enough, qualify for capital gains treatment. Second, different treatment of capital gains and dividends affects the relative attractiveness of distributing corporate profits via share buybacks versus dividends. Third, capital gains tax preferences can affect the allocation of capital across industries and locations, due to sheltering opportunities such as like-kind exchanges in real estate and oil and gas, investments in Opportunity Zones, and incomplete recapture of depreciation deductions following asset sales. Reforming capital gains taxation will thus also reduce wasteful effort by taxpayers and their planners to devote resources to circumventing tax liabilities by exploiting preferential capital gains rates and sheltering opportunities.

\subsection{Capital gains tax changes and investment behavior}

One reason to be skeptical of the revenue potential of capital gains tax increases is that tax increases might impact economic growth. Many critics of capital income taxes argue that low rates induce business creation by allowing investors to reap a larger share of the gains they create (Feldstein, 2006).

Indeed in the Bush Administration, one rationale for cutting capital gains rates was incentivizing entrepreneurship. According to the 1990 Economic Report of the President, "[m]uch of the return to entrepreneurs... comes through increasing the value of the business. Reducing the tax rate on capital gains will provide a climate that encourages businesses to invest in new technologies and products" (President and CEA, 1990). If large, such investment and entrepreneurship effects would amplify realization elasticities by shrinking the future corporate tax base in the case of a capital gains tax increase. ${ }^{9}$

But the case for large investment effects of lower capital gains rates appears overstated. First, preferential capital gains treatment incentivizes some income sheltering that may cause misallocation and prevent capital from being employed in its most productive use. Second, the majority of venture capital comes from large institutions like pension funds, endowments of universities, charitable foundations, and sovereign wealth funds, which are already tax-exempt. ${ }^{10}$ Third, it is hard to imagine entrepreneurs making decisions about investment

\footnotetext{
${ }^{9}$ Another reason why considering dynamics and longer horizons would be valuable is that longer horizons are needed to detect and quantify these effects.

${ }^{10}$ This was a point made by early work by Poterba (1989) and is even more true today.
} 
and risk on the basis of the capital gains tax regime: Mark Zuckerberg was not focusing on the capital gains tax when he was in his dorm room coding up Facebook. Bell, Chetty, Jaravel, Petkova and Van Reenen (2019) reach the same conclusion based on comprehensive data on U.S. inventors, arguing that tax cuts do not produce more Einsteins. Finally, in a related context, empirical evidence suggests that dividend tax cuts that decrease firms' cost of capital in similar ways to the capital gains tax do not affect investment (Yagan, 2015$).{ }^{11}$

\section{Implications for Scorekeeping and Revenue Estimates}

\subsection{Illustrative revenue estimates under different assumptions}

Table 1 shows our realization and revenue estimates for capital gains tax rate increases. The first column starts with CBO's projections for realizations from 2020 to 2029. While the amount of realizations itself is endogenous, the CBO projections of approximately $\$ 1$ trillion of realizations per year over the next decade provide a useful starting point. ${ }^{12}$ At a $20 \%$ tax rate, the table shows that the baseline capital tax revenues amount to around $\$ 200$ billion a year.

We consider two tax changes. The first is a 2 percentage point increase in the rate, which allows us to compare our approach to published scores from JCT. ${ }^{13}$ Table 1 shows how much realizations shrink under different elasticity assumptions. When $e=0$, realizations remain at their baseline level. But when $e=-0.3$ and $e=-0.7$, the baseline realizations shrink by $3 \%(=9.5 \% \times-0.3)$ and $7 \%$, respectively. These are on the lower and upper end of the varied realization elasticities estimated by prior work. ${ }^{14}$ Applying the new $22 \%$ tax rate to the smaller realization levels results in less revenue than the additional $\$ 20 \mathrm{~B}$ per year that would result if there were no behavioral response. With $e=-0.3$ and $e=-0.7$, the annual gains are $\$ 13.7$ billion and $\$ 5.3$ billion, respectively.

The JCT scores capital gains hikes of 2 percentage points as generating around $\$ 70$ billion over ten years, which is roughly in the same ballpark as our ten-year estimate using the crude elasticity approach with $e=-0.7$ of $\$ 54$ billion. We suspect some of this difference may reflect more careful consideration of other components that our crude elasticity-based approach misses, but we view this as somewhat validating that the crude approach is on the same order of magnitude as this public JCT score.

The second tax change of interest is doubling the rate from $20 \%$ to $40 \%$, which would raise the capital gains rate to top ordinary income levels. This change requires much more extrapolation from observed variation in the data and more elaborate methods to model behavioral responses to such large changes. Nonetheless, it is

\footnotetext{
${ }^{11}$ In contrast, Moon (2020) presents evidence that a capital gains tax reform in South Korea had substantial effects on corporate investment.

${ }^{12}$ Note that CBO's baseline has capital gains as a share of GDP falling slightly, which is why the table shows a relatively stable base of realizations despite higher nominal GDP. If the capital gains share of GDP is stable, then the revenue potential is even greater than the estimates we present.

${ }^{13}$ Note that the CBO cites the JCT as the source for the table of revenue effects. https://www.cbo.gov/budget-options/ 2018/54788.

${ }^{14}$ Specifically, we take $e=-0.3$ from Agersnap and Zidar (2020) discussed above (and pick the lower end of their range to reflect an elasticity that may be consistent with eliminating stepped-up basis and including other base broadeners); $e=-0.7$ is the midpoint of the current JCT and Treasury elasticity estimates of -.68 and -.72 , which we believe may be based in part on the headline estimate of -0.72 in Dowd, McClelland and Muthitacharoen (2015). The $9.5 \%$ comes from the rate change of 2 p.p. divided by the average of the initial rate of $20 \%$ and the post-change rate of $22 \%$.
} 
striking to see how much elasticity assumptions affect revenue scores. Using an elasticity of $e=-0.3$, raising the tax rate to $40 \%$ would raise just over $\$ 1.2$ trillion over ten years. ${ }^{15}$ With the elimination of stepped-up basis, this estimate rises to $\$ 1.4$ trillion. ${ }^{16}$

Comparing this figure to the case of $e=-0.7$ illustrates the striking behavioral adjustments that are implied by such an elasticity. We can see this in multiple ways. First, in the Auerbach (1989) model, we can relate behavioral responses to changes in the frequency of realization and the extent of deferral until death or via charitable contribution. In the Appendix, we find that with $e=-0.7$, if the effect on the capital gains tax base is driven solely by an increase in deferred realizations, the share of unrealized gains would have to rise from $50 \%$ to nearly $70 \%$. If the effect is driven by an increase in turnover, then turnover would decrease from once every three years (CBO and JCT, 2016) to once every 13 years, increasing by a factor of four.

For the case of $e=-0.3$, the impact on unrealized gains would be half as large. The impact on turnover would also be about half as large, as turnover rises from once every three years to once every seven years. Thus, the change in underlying investor behavior predicted by applying $e=-0.7$ is significantly more dramatic than in the case of $e=-0.3$. More explicit modeling of turnover behavior and the distribution of unrealized gains would help provide discipline when modeling large tax changes. ${ }^{17}$

Second, simply applying $e=-0.7$ to the CBO's projections for realized gains implies a gain of only $\$ 140$ billion over ten years, almost ten times smaller than our estimate using $e=-0.3 .{ }^{18}$ Figure 7 shows the sensitivity of revenue estimates to a range of elasticities from zero to one. Adjusting our preferred elasticity toward zero (e.g., if rate hikes are coupled with base-broadening reforms like the elimination of step-up in basis or death as a realization event) produces estimates approaching $\$ 2$ trillion. ${ }^{19}$

These calculations are far from a final word on the tax revenue at stake from these reforms. Moreover, we suspect that, for a large change in tax rates, scorekeepers have developed more elaborate revenue models than our stylized approach implies. Our objective is to illustrate that the many issues we raise above suggest the capital gains tax base overall is likely less elastic than previously understood. Therefore, should scorekeepers be moved to revisit elasticity assumptions and the modeling of deferred gains, the impact on official revenue estimates could be substantial.

\footnotetext{
${ }^{15}$ The mechanical revenue of a $40 \%$ rate on a $\$ 1$ trillion base is $\$ 400$ billion in annual revenue, or an additional $\$ 200$ billion in revenue per year. Using an elasticity of $e=-0.3$ shrinks the base by $20 \%$ (which is $-0.3 \times \frac{20}{(20+40) / 2}$ ) to $\$ 800$ billion, generating around $\$ 320$ billion in annual revenue, or about $\$ 120$ billion more per year.

${ }^{16}$ The impact of stepped-up basis elimination is based on the JCT score, which at current rates is estimated to raise $\$ 105$ billion over a decade (CBO, 2018). Since we are focused on the revenue effect of raising capital gains rates to ordinary income levels, we double this estimate. An alternative approach would be to follow Penn-Wharton Budget Model and scale the realization elasticity down by $20 \%$ from -0.65 to -0.52 (https://budgetmodel.wharton.upenn.edu/issues/2020/9/14/ biden-2020-analysis). Of course, a more sophisticated approach to estimating the interaction of various capital gains reform proposals would yield a more accurate estimate.

${ }^{17}$ This calculation abstracts from reductions in the overall base due to real responses, which can also contribute to the change in gains and place less burden on turnover in accounting for the total response.

${ }^{18}$ Using $e=-0.7$, the $\$ 1$ trillion baseline realizations shrink by $47 \%$ (which is $-0.7 \times \frac{20}{(20+40) / 2}$ ) to $\$ 530$ billion per year. With only $\$ 530$ billion in realizations, a $40 \%$ tax rate would raise $\$ 212$ billion, or just $\$ 12$ billion more than the baseline revenues of $\$ 200$ billion per year.

${ }^{19}$ To facilitate comparisons to prior estimates, we express calculations in terms of elasticities with respect to the tax rate. In general, we prefer the net-of-tax formulation because it measures the relevant price governing behavior, is standard in the broader tax literature, and better reflects the economic magnitude of the tax shock. The net-of-tax estimates are similar to the estimates we present and do not alter the conclusion.
} 
Revenue estimates from scorekeeping community. To our knowledge, there are no recent official estimates available for raising capital gains rates to ordinary income levels. Estimates offered during this election cycle from unofficial scorekeepers (see Table 2) suggest that large increases in capital gains rates can raise significant revenue. The general consensus appears to be that an increase in capital gains rates of the size we contemplate is likely to raise hundreds of billions of dollars in the coming decade. Still, these scores are far below the crude estimate that we offer in Section 5.1.20 In part, this difference reflects the much more significant taxpayer response assumed by the scorekeeping community, which we think is worth revisiting in light of the considerations we offer.

\subsection{Elasticity depends on broader capital gains context}

Unique features of capital gains taxation make the tax base more sensitive to rate changes than other types of taxes (Dowd and Richards, 2021). Most obviously, the existence of a step-up in basis upon the death of the taxpayer dissuades holders of unappreciated assets from realizing their gains in a high-rate environment, in the absence of consumption needs or a desire to diversify. Eliminating stepped-up basis would diminish incentives to lock-in gains, which is why we estimate an added $\$ 200$ billion in additional capital gains taxes collected if raising capital gains rates is combined with this change. Making death a realization event for capital gains tax collection would likely raise even more, because the value of deferral, especially in a low-rate environment, would be minimal if taxes were sure to be collected at death (abstracting away from policy risk that such a change would be rolled back by future policymakers).

In the current code, deferring gains until death is not the only capital gains avoidance tactic. When an individual donates an asset to charity (e.g., share of stock) that has appreciated in value, capital gains on that asset go untaxed, and the individual receives a credit equivalent to the full value of the gift, despite not paying any taxes on the gain. Further, investors can place existing assets with accumulated gains into Opportunity Zones (meant to spur investment in economically distressed communities) to defer payment of capital gains; or can avoid taxation all together, for example through the use of like-kind exchanges for real estate transactions. On top of this, investing in small businesses can mean up to $\$ 10$ million in gains is excluded from capital gains taxation. Broadening the capital gains tax base by limiting these preferences raises the revenue potential of capital gains reform efforts. Conversely, while significant sheltering opportunities exist, there is a legitimate concern that raising the capital gains rate will result in taxpayers relying more on existing tools to shield gains from taxation, thus limiting the potential of reform.

The elasticities that we use are based on the current capital taxation regime, including a step-up in basis at death, which amplifies the incentive to respond to capital gains tax changes. A broader overhaul of capital gains taxation - which raises rates while also eliminating sheltering opportunities - could result in a lower realization elasticity, and thus even more revenue potential, than our estimates suggest.

\footnotetext{
${ }^{20}$ One difference between our back-of-the-envelope calculation and these scores is the size of the tax base. These scores focus on a proposal to raise rates only for those whose AGI exceeds one million, who collectively account for around $70 \%$ of all taxable realizations based on $2019 \mathrm{SCF}$ data. Applying our approach to this group would result in $70 \%$ of the revenue from raising rates across the board or $\$ 840$ billion $+\$ 200$ billion $=\$ 1040$ billion.
} 


\subsection{Transparency would improve policy analysis of alternative reforms}

Transparency on how dynamic adjustments are made in official scores would be valuable for several reasons. First, this transparency will facilitate discussion between professional scorekeepers and outside experts about the extent to which models can be improved and new data collected. Second, it will facilitate comparison of estimates across a broader set of proposals with confidence that consistent scorekeeping practices are applied. Ensuring comparability across scores produced for different proposals is essential to informing the policy process. And comparability depends on transparency of the assumptions that underlie these estimates.

A few examples are illustrative. Mark-to-market capital gains proposals have yet to be officially scored. But some available estimates of the likely revenue potential suggest that nearly $\$ 200$ billion annually could be raised (Gravelle, 2019; Batchelder and Kamin, 2019). By way of comparison, JCT estimates that taxing capital gains at death would yield about $\$ 40$ billion annually (absent any behavioral changes). ${ }^{21}$ It is unclear how to get from this realization-at-death score to a mark-to-market estimate of nearly 5 times that amount: In a low rate environment, the value of deferral is negligible, so the two approaches should yield similar revenue.

Another example concerns the score for eliminating the carried interest loophole. The JCT approach to scoring this provision seems to assume even larger shifting responses than in the case of capital gains tax increases, presumably because they model such a change in the absence of other changes to taxing gains. Essentially, the assumption is that fund managers will devise alternative contractual arrangements to reconstruct the status quo, so that revenues ultimately rise very little. It is unclear (to us) whether there is an empirical basis for this assumption.

\subsection{A process suggestion}

Transparency is a double-edged sword. Given the importance of official scores to legislative decision-making, making the assumptions underlying scorekeepers' estimation publicly available will invite greater lobbying around those assumptions by supporters and critics of different reforms.

Our proposal is not to open the floodgates with respect to scorekeeping writ large. A natural structure is in place: CBO already has a panel of advisers who provide input on economic issues. This group or a related subgroup of experts can be convened to advise JCT, as well as CBO and the Treasury Office of Tax Analysis. It will be important for diverse views to be represented in this body, and it will be valuable to work with the full set of scorekeepers to select a panel who is thoughtful and likely to be taken seriously by the revenue estimating community. Short of such a formal gathering, promoting informal conversations and collaborations between scorekeepers and academics would facilitate advancing the research frontier in the most useful directions.

\section{Conclusion}

The appropriate tax treatment of capital gains is a major issue. Historically, the consensus of scorekeepers has been that very sizable behavioral effects diminish the revenue-raising potential of rate hikes, because they

\footnotetext{
${ }^{21}$ From the JCT's 2019 tax expenditure estimates: https://www.jct.gov/publications/2019/jcx-55-19/.
} 
encourage taxpayers to lock-in gains and avoid taxation, potentially indefinitely. We believe this conclusion is worth revisiting in light of recent research, an improved understanding of dynamic responses via medium-run investor behavior, and the recent evolution in the composition of capital gains.

Indeed, we argue the revenue potential from substantially increasing tax rates on capital gains may be greater than previously understood. A crude estimate suggests that raising capital gains rates to ordinary income levels could raise vastly more revenue than what is implied by applying conventional elasticities. The striking difference suggests there is much to be gained from refining the approach to scoring capital gains tax reforms.

Our call to action is borne from a position of enormous respect and admiration for the integrity and seriousness of the scorekeepers. The ultimate goal is to continue to advance our understanding of taxpayer behavior and the revenue potential of capital gains (and other) tax reform efforts to inform the policymaking process.

For example, it would be valuable for scorekeepers to explicitly model the consequences of capital gains tax changes on turnover, taking into account the large stock of yet unrealized gains, how it varies across types of gains, and how it may evolve. We're optimistic that focusing on turnover is one avenue towards potentially improving revenue estimates and the analysis of capital gains taxation. 


\section{References}

Agersnap, Ole, and Owen Zidar. 2020. "The Tax Elasticity of Capital Gains and Revenue-Maximizing Rates." NBER Working Paper No. 27705.

Auerbach, Alan J. 1989. "Capital gains taxation and tax reform." National Tax Journal, 42(3): 391-401.

Auten, Gerald E, and Joseph J Cordes. 1991. "Policy watch: cutting capital gains taxes." Journal of Economic Perspectives, 5(1): 181-192.

Barber, Brad M, and Terrance Odean. 2000. "Trading is hazardous to your wealth: The common stock investment performance of individual investors." Journal of Finance, 55(2): 773-806.

Batchelder, Lily L., and David Kamin. 2019. "Taxing the Rich: Issues and Options." Available at SSRN.

Bell, Alex, Raj Chetty, Xavier Jaravel, Neviana Petkova, and John Van Reenen. 2019. "Who becomes an inventor in America? The importance of exposure to innovation." The Quarterly Journal of Economics, 134(2): 647-713.

CBO. 2018. "Options for Reducing the Deficit: Change the Tax Treatment of Capital Gains From Sales of Inherited Assets." https://www.cbo.gov/budget-options/54792.

CBO and JCT. 2016. "The Distribution of Asset Holdings and Capital Gains." https://www.cbo.gov/ sites/default/files/114th-congress-2015-2016/reports/51831-capitalgains .pdf.

Dowd, Tim, and Robert McClelland. 2019. "The Bunching of Capital Gains Realizations." National Tax Journal, 72(2): 323-358.

Dowd, Tim, and Zach Richards. 2021. "Contextualizing Elasticities for Policymaking: Capital Gains and Revenue-Maximizing Tax Rates." Available on SSRN: https://papers.ssrn.com/sol3/papers.cfm? abstract_id=3767121.

Dowd, Tim, Robert McClelland, and Athiphat Muthitacharoen. 2015. "New evidence on the tax elasticity of capital gains." National Tax Journal, 68(3): 511.

Feldstein, Martin. 2006. "The effect of taxes on efficiency and growth." NBER Working Paper No. 12201.

Gravelle, Jane. 1991. "Limits to Capital Gains Feedback Effects." Congressional Research Service, Library of Congress.

Gravelle, Jane. 2019. "Mark-to-Market Taxation of Capital Gains." https://www.taxpolicycenter.org/ sites/default/files/mark-to-market_taxation_of_capital_gains.pdf.

Joint Committee on Taxation, Staff. 1990. "Explanation of Methodology Used to Estimate Proposals Affecting the Taxation of Income from Capital Gains." Vol. JCS-12-90.

Moon, Terry S. 2020. "Capital gains taxes and real corporate investment." Princeton University Working Paper.

Odean, Terrance. 1998. "Are investors reluctant to realize their losses?" Journal of Finance, 53(5): 17751798.

Odean, Terrance. 1999. "Do investors trade too much?" American Economic Review, 89(5): 1279-1298.

Poterba, James M. 1989. "Venture Capital and Capital Gains Taxation." Tax Policy and the Economy, $47-67$.

President and CEA. 1990. "Economic Report of the President." https://fraser.stlouisfed.org/title/ economic-report-president-45/1990-8161.

Saez, Emmanuel, Joel Slemrod, and Seth H. Giertz. 2012. "The Elasticity of Taxable Income with Respect to Marginal Tax Rates: A Critical Review." Journal of Economic Literature, 50(1): 3-50. 
Smith, Matthew, Danny Yagan, Owen Zidar, and Eric Zwick. 2019. "Capitalists in the Twenty-first Century." Quarterly Journal of Economics, 134(4): 1675-1745.

Smith, Matthew, Owen M Zidar, and Eric Zwick. 2020. "Top Wealth in America: New Estimates and Implications." Working Paper.

Stiglitz, Joseph E. 1983. "Some aspects of the taxation of capital gains." Journal of Public Economics, 21(2): 257-294.

Yagan, Danny. 2015. "Capital tax reform and the real economy: The effects of the 2003 dividend tax cut." American Economic Review, 105(12): 3531-63. 
Figure 6: Evolution of Wealth and Capital Gains Tax Rates

(a) Fixed income assets

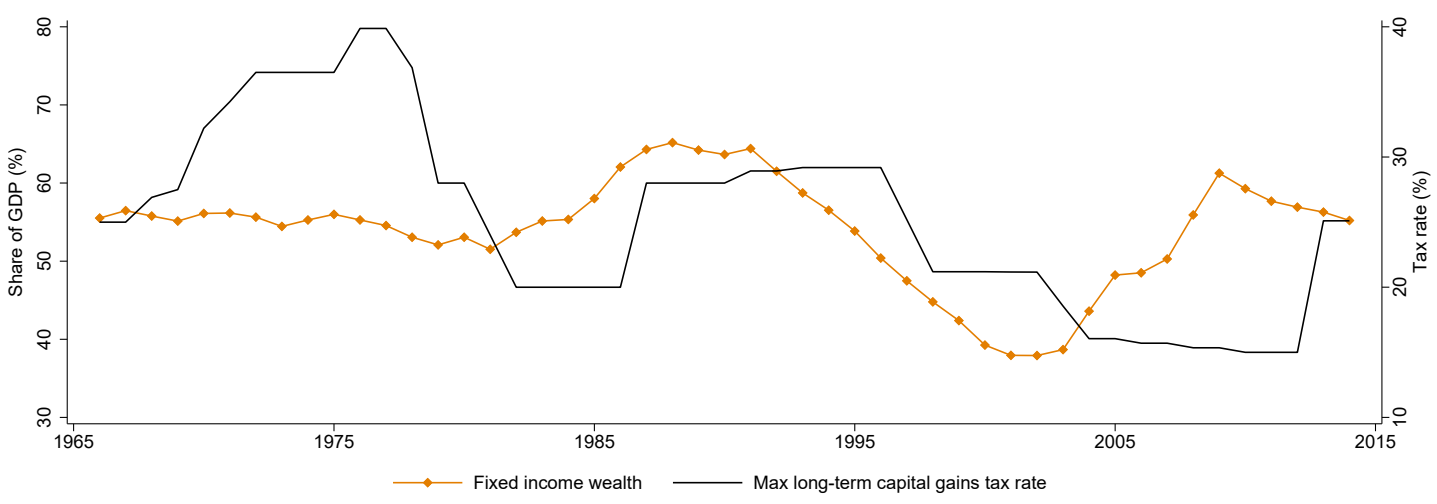

(b) Pass-through equity wealth

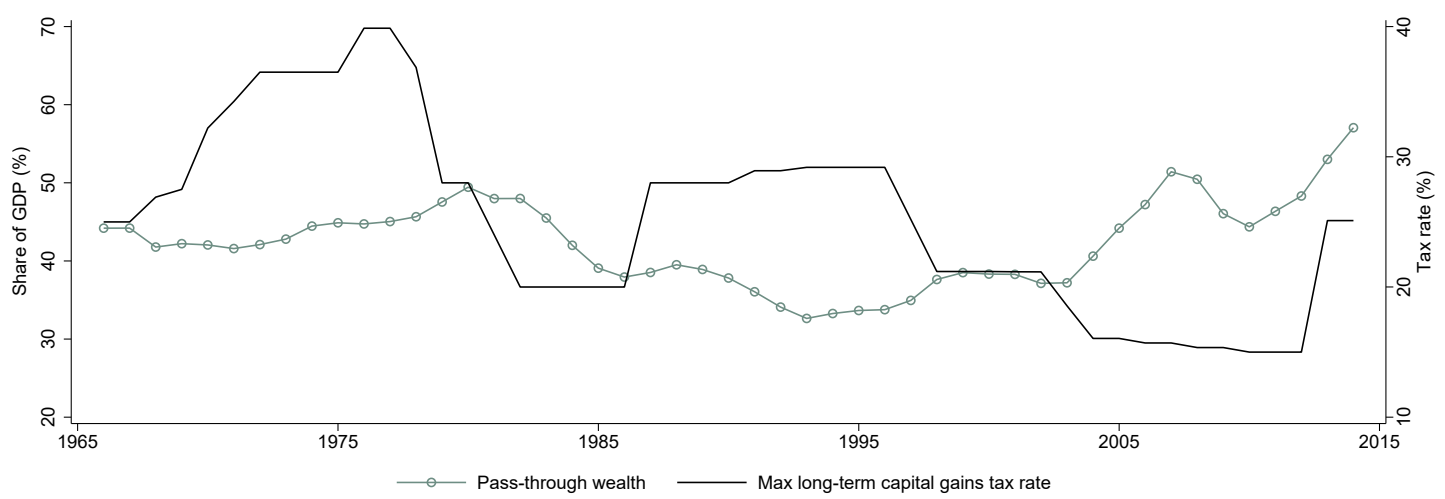

(c) Equity and fixed income wealth

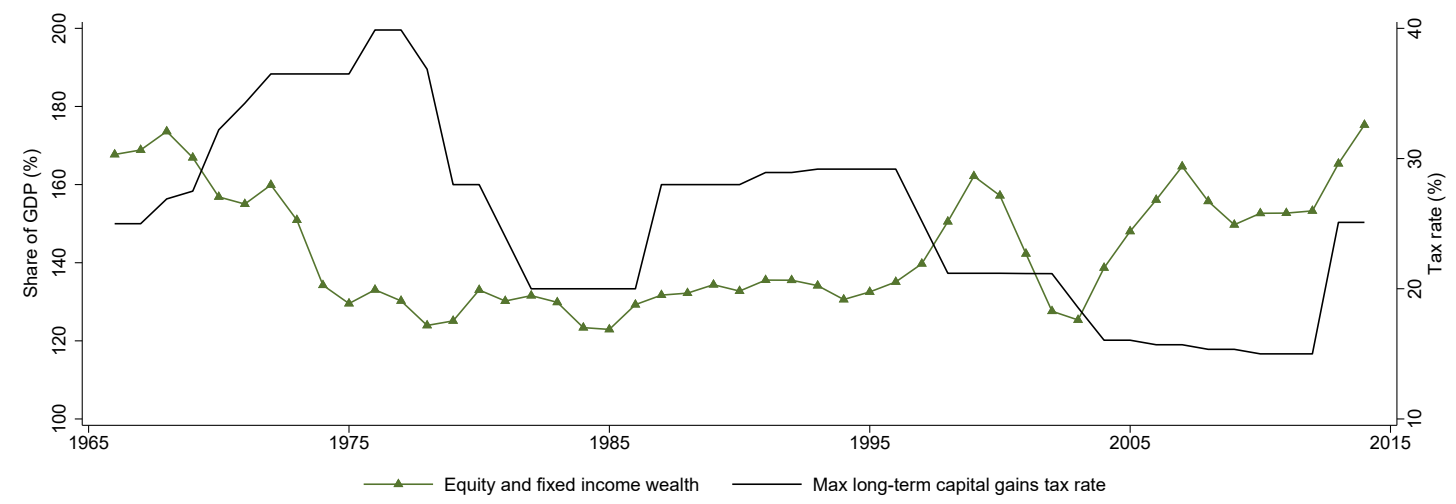

Notes: These graphs plot fixed income assets, pass-through equity wealth, total equity and fixed income wealth, and the maximum long-term capital gains tax rates between 1960 and 2014 as a share of GDP. In panel (a), fixed income assets include taxable and non-taxable fixed income assets, in addition to non-interest bearing deposits. In panel (b), pass-through wealth includes assets from partnerships, sole-proprietorships, and S-corporations. In panel (c), equity includes C-corporation and pass-through assets. Data on wealth from Smith, Zidar, and Zwick (2020). Data on tax rates from the U.S. Treasury (https://www.treasury.gov/resource-center/tax-policy/tax-analysis/Documents/ Taxes-Paid-on-Capital-Gains-for-Returns-with-Positive-Net-Capital-Gains.pdf) and the Tax Foundation (https: //taxfoundation.org/federal-capital-gains-tax-collections-1954-2009/). GDP data from the World Bank (https: //data. worldbank. org/indicator/NY. GDP. MKTP.CD). 
Figure 7: Illustrative Revenue Estimates for Different Elasticities

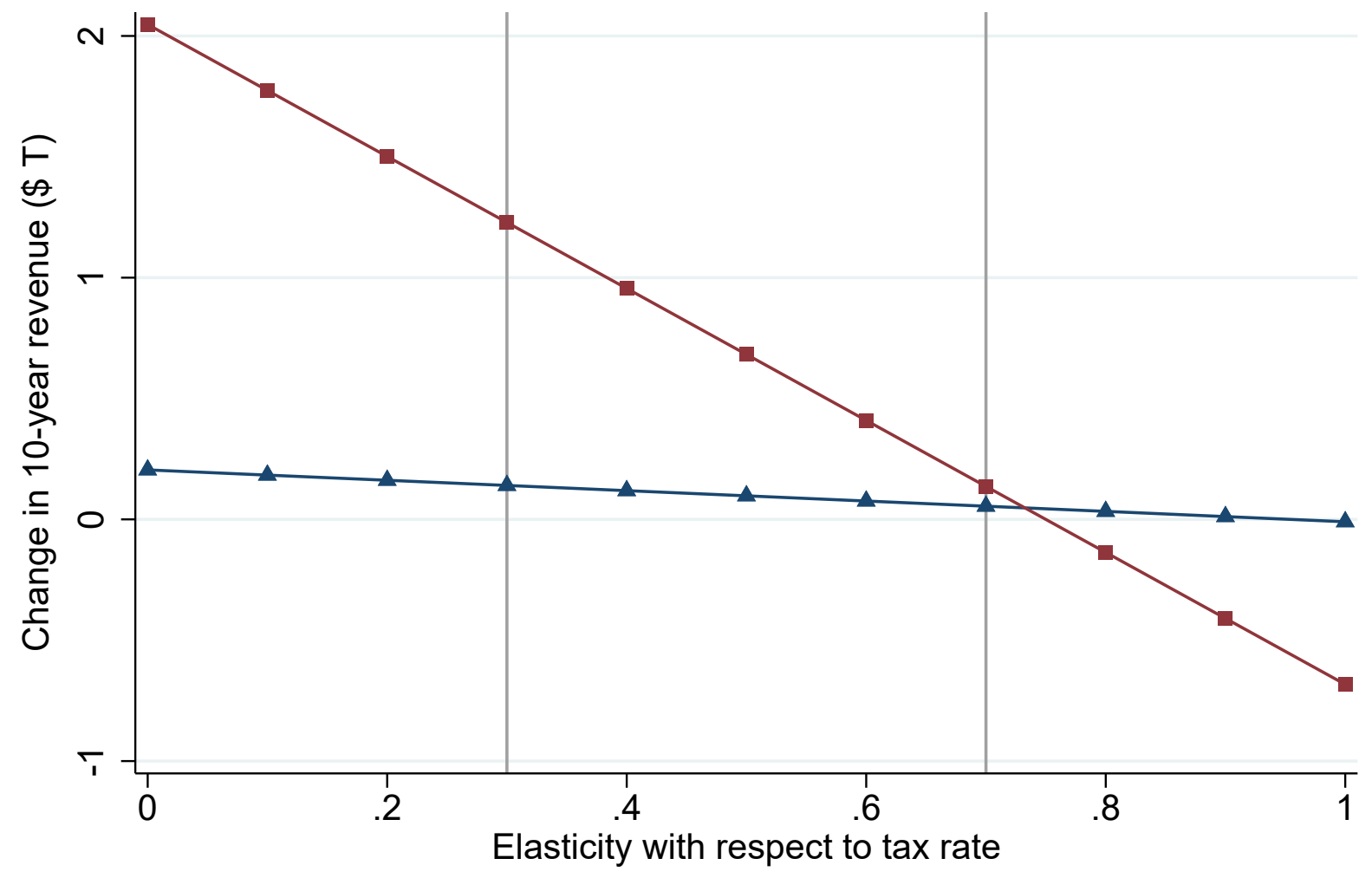

Notes: We base our estimates on CBO projections of capital gains realizations from 2020 to 2029 (accessible at https://www. cbo.gov/data/budget-economic-data under "Revenue projections, by category"). See Table 1 for underlying CBO projections and realizations estimates corresponding to $e=-.3$ and $e=-0.7$. We assume a starting tax rate of $20 \%$. When multiplied by $-\frac{1-0.22}{0.22}$, tax rate elasticities at a tax rate of $22 \%$ become net-of-tax rate elasticities. 
Table 1: Realization and Revenue Estimates for 2 p.p. and 20 p.p. Tax Rate Increases, by Elasticity

\begin{tabular}{|c|c|c|c|c|c|c|c|c|c|c|c|c|c|c|}
\hline & & & \multicolumn{6}{|c|}{$\mathrm{t}=22 \%$} & \multicolumn{6}{|c|}{$\mathrm{t}=40 \%$} \\
\hline & \multicolumn{2}{|c|}{ CBO Projections } & \multicolumn{3}{|c|}{ Realizations } & \multicolumn{3}{|c|}{ Revenue } & \multicolumn{3}{|c|}{ Realizations } & \multicolumn{3}{|c|}{ Revenue } \\
\hline & Realizations & Revenue & $\mathrm{e}=\mathbf{0}$ & $e=-0.3$ & $e=-0.7$ & $\mathrm{e}=\mathbf{0}$ & $\mathrm{e}=-0.3$ & $e=-0.7$ & $\mathrm{e}=\mathbf{0}$ & $\mathrm{e}=-0.3$ & $e=-0.7$ & $\mathrm{e}=\mathbf{0}$ & $e=-0.3$ & $e=-0.7$ \\
\hline 2020 & 1,013 & 203 & 1,013 & 984 & 945 & 223 & 216 & 208 & 1,013 & 810 & 540 & 405 & 324 & 216 \\
\hline 2021 & 1,009 & 202 & 1,009 & 980 & 942 & 222 & 216 & 207 & 1,009 & 807 & 538 & 404 & 323 & 215 \\
\hline 2022 & 1,004 & 201 & 1,004 & 975 & 937 & 221 & 215 & 206 & 1,004 & 803 & 535 & 402 & 321 & 214 \\
\hline 2023 & 987 & 197 & 987 & 959 & 921 & 217 & 211 & 203 & 987 & 790 & 526 & 395 & 316 & 211 \\
\hline 2024 & 986 & 197 & 986 & 958 & 920 & 217 & 211 & 202 & 986 & 789 & 526 & 394 & 316 & 210 \\
\hline 2025 & 996 & 199 & 996 & 968 & 930 & 219 & 213 & 205 & 996 & 797 & 531 & 398 & 319 & 212 \\
\hline 2026 & 1,016 & 203 & 1,016 & 987 & 948 & 224 & 217 & 209 & 1,016 & 813 & 542 & 406 & 325 & 217 \\
\hline 2027 & 1,043 & 209 & 1,043 & 1,013 & 973 & 229 & 223 & 214 & 1,043 & 834 & 556 & 417 & 334 & 223 \\
\hline 2028 & 1,074 & 215 & 1,074 & 1,043 & 1,002 & 236 & 230 & 221 & 1,074 & 859 & 573 & 430 & 344 & 229 \\
\hline 2029 & 1,110 & 222 & 1,110 & 1,078 & 1,036 & 244 & 237 & 228 & 1,110 & 888 & 592 & 444 & 355 & 237 \\
\hline SUM & 10,238 & 2,048 & 10,238 & 9,945 & 9,555 & 2,252 & 2,188 & 2,102 & 10,238 & 8,190 & 5,460 & 4,095 & 3,276 & 2,184 \\
\hline
\end{tabular}

Notes: CG base taken from January 2020 CBO predictions for capital gains realizations over the next ten years (accessible at https://www. cbo.gov/ data/budget-economic-data under "Revenue projections, by category"). We assume a starting tax rate of $20 \%$ to compute baseline total revenues. 
Table 2: Unofficial estimates of revenue potential from taxing capital gains at ordinary income levels

\begin{tabular}{|c|c|c|c|}
\hline Source & $\begin{array}{l}\text { Revenue } \\
\text { estimate } \\
(\$ B)\end{array}$ & Elasticities & Notes \\
\hline $\begin{array}{l}\text { Penn Wharton } \\
\text { Budget Model }\end{array}$ & 382 & $\begin{array}{l}\text { With step-up in basis: }-0.66 \\
\text { Eliminating step-up in basis: }-0.53\end{array}$ & $\begin{array}{l}\text { Reported estimate includes } \$ 178 \mathrm{~B} \text { from } \\
\text { taxing capital gains and dividends at or- } \\
\text { dinary rates, and } \$ 204 \mathrm{~B} \text { from repealing } \\
\text { step-up in basis }\end{array}$ \\
\hline Tax Foundation & 469 & $\begin{array}{l}\text { Long-run: }-0.79 \\
\text { Transitory: }-1.2 \text { (year } 1 \text { ) and }-1.0 \\
\text { (year 2) }\end{array}$ & $\begin{array}{l}\text { Tax capital gains and dividends at the } \\
\text { same rate as ordinary income for those } \\
\text { with income } \$ 1 \mathrm{M}+\text { and repeal step-up in } \\
\text { basis }\end{array}$ \\
\hline $\begin{array}{l}\text { Tax Policy Cen- } \\
\text { ter }\end{array}$ & 373 & $\begin{array}{l}\text { With step-up in basis: }-0.7 \\
\text { Eliminating step-up in basis: }-0.4\end{array}$ & $\begin{array}{l}\text { Tax capital gains and dividends at the } \\
\text { same rate as ordinary income for those } \\
\text { with income } \$ 1 \mathrm{M}+\text { and tax unrealized } \\
\text { gains at death }\end{array}$ \\
\hline
\end{tabular}

Notes: All rows present 10 year revenue estimates for raising the tax on capital gains and dividends to ordinary rates $(39.6 \%)$ for income above $\$ 1$ million and eliminating the step-up in basis at death.

Penn Wharton Budget Model revenue and elasticity estimates can be found at https:

//budgetmodel. wharton. upenn. edu/issues/2020/3/10/the-biden-tax-plan-updated

and https://budgetmodel. wharton. upenn.edu/issues/2019/12/4/

the-revenue-maximizing-capital-gains-tax-rate-with-and-without-stepped-up-basis-at-death.

Tax Foundation revenue and elasticity estimates are available at https://taxfoundation.org/ joe-biden-tax-plan-2020/ and https://taxfoundation.org/2020-capital-gains-tax-proposals/.

Estimates from the Tax Policy Center can be found at https://www.taxpolicycenter.org/ model-estimates/updated-analysis-former-vice-president-bidens-tax-plan-october-2020/ t20-0246-former and https://www.taxpolicycenter.org/sites/default/files/publication/158624/ An_Analysis_of_Former_Vice_President_Bidens_Tax_Proposals_1_2.pdf. 


\section{Appendix For Online Publication}

\section{A A model of capital gains realizations}

This appendix describes and updates the asset turnover model in Auerbach (1989), which we use to relate capital gains elasticities to changes in investor behavior. The two key parameters are $f$, which is the fraction of assets that never face capital gains, and $\delta$, which is the fraction of assets that face capital gains and are sold every year. The main idea is that a given change in capital gains realizations can be related to changes in these two parameters, which represent investors holding assets until death and asset turnover frequency.

We need to define a few more variables to relate capital gains realizations $G_{t}$ in to these two key parameters. The nominal value of assets sold in year $t$ is denoted $a_{t}$, and $g$ is the annual growth rate of asset value (and output growth). With these components, we can express capital gains realizations $G_{t}$ as the sum of accumulated gains from assets held at different durations:

$$
G_{t}=g \delta a_{t-1}+\left[(1+g)^{2}-1\right] \delta(1-\delta) a_{t-2}+\left[(1+g)^{3}-1\right] \delta(1-\delta)^{2} a_{t-3}+\ldots
$$

Auerbach (1989) shows that one can express the steady-state ratio of realizations to sales at each date:

$$
\frac{G}{a}=\frac{g}{g+\delta}
$$

As Auerbach argues, the total value of assets ever sold $S$ is sum of those last realized one year ago, at current value, $(1+g) a_{t-1}$ plus those two years ago, at current value, $(1+g)^{2}(1-\delta) a_{t-2}$, plus those three years ago, at current value, $(1+g)^{3}(1-\delta)^{2} a_{t-3}$, etc. Given the steady state condition that $a_{t}=(1+g) a_{t-1}$, the sum $S=a_{t}+(1-\delta) a_{t-1}+(1-\delta)^{2} a_{t-2}+\ldots=\frac{a_{t}}{\delta}$. Since a fraction $f$ of all assets are never realized, this result (i.e., $\left.A=(1-f) \frac{a_{t}}{\delta}\right)$ and equation A.2 imply that the ratio of gains to assets each year is:

$$
\frac{G}{A}=(1-f) \frac{g \delta}{g+\delta}
$$

Thus, the ratio of realized gains to the total value of assets that are ever sold is a function of our two main parameters $f$ and $\delta$, as well as the rate of growth $g$. We cannot observe $f$ and $g$ directly, but we can re-arrange these expressions to estimate them using nominal rates of return, the ratio of gains to sales, and the ratio of gains to assets. Specifically, we can rewrite equation A.2 and A.3:

$$
\begin{aligned}
& \delta=\frac{g\left(1-\frac{G}{a}\right)}{\frac{G}{a}} \\
& f=1-\frac{\frac{G}{A}(g+\delta)}{g \delta}
\end{aligned}
$$

Auerbach (1989) sets $g=.1$ and estimates that $\frac{G}{A}=0.033$ and $\frac{G}{a}=0.303$. The resulting estimates using inputs from the late 1970s and early 1980s give $\delta=0.23$ and $f=0.526$, suggesting that half of assets never face capital gains, and those that do turn over roughly every four years.

Updating the inputs to this calculation gives slightly higher estimates of $\delta$ and similar estimate of $f$. If we set $g=.06$ based on nominal annual wealth growth since $1990, \frac{G}{A}=.0257$, and $\frac{G}{a}=0.158$, then we get updated estimates $\hat{\delta}=.32$ and $\hat{f}=.49 .^{22}$

\section{A.1 Using model to quantify implications of elasticity estimates for $\delta$ and $f$}

Taking log differences of A.3, gives an expression for log changes in the realizations in terms of parameters:

$$
\Delta \ln G=\Delta \ln (1-f)+\Delta \ln \left(\frac{g \delta}{g+\delta}\right)+\Delta \ln A
$$

\footnotetext{
${ }^{22}$ Note that $\frac{G}{A}=.0257$ is the ratio of realized gains divided by household public and private equity holdings plus real estate wealth less housing wealth. For $\frac{G}{a}=0.158$, we use the ratio of net gains to sales price in Table 1C, which has long term gains in 2010. https://www.irs.gov/pub/irs-soi/soi-a-inca-id1604.pdf
} 
We can use this expression to relate our parameters to capital gains realization elasticities, (i.e., $e=\frac{\Delta \ln G}{\Delta \ln \tau}$ ) with respect to capital gains tax rates $\tau$. For a change in tax rates and a given elasticity, the change in realizations is $\Delta \ln G=e \times \Delta \ln \tau$. Using this expression allows us to go from an elasticity value and a tax change to see how much $f$ and $\delta$ might have to change.

$$
e \times \Delta \ln \tau=\Delta \ln (1-f)+\Delta \ln \left(\frac{g \delta}{g+\delta}\right)+\Delta \ln A
$$

Quantitatively, we can start with the updated calibration values described above: $f_{0}=.49$ and $\delta_{0}=.32$, $g=.06$ as a baseline. Consider a capital gains tax rate increase that increases rates from $\tau_{0}=.22$ to $\tau_{1}=.396$, so $\Delta \ln \tau \approx 60 \%{ }^{23}$ With an elasticity of -.7 , the left-hand-side is $e=-0.7 \times .6=-.42$, which means that gains would fall by $42 \%$. Applying equation A.7, we can obtain this decline by $42 \%$ through changes in $f$, $\delta$, or some combination (assuming, for simplicity, that $\Delta \ln A=0$ ). Using only changes in $f$, we'd need $\Delta \ln (1-f)=-.42 \Rightarrow f_{1}=66.5$. In other words, if all the response to the tax increase came from changes $f$, the share of gains that are held until death would have to increase by 17.5 percentage points from an initial level of $f_{0}=.49$. Using only changes in $\delta$, we'd get $\delta_{1}=.075$, which is a substantial decline in asset turnover frequency relative to an initial value of $\delta_{0}=.32$. With an elasticity of $e=-0.3$, the percentage point increase in $f$ would be half as large (i.e., the increase would be 8.5 p.p.), and the value of $\delta_{1}=.15$ would be twice as high.

\footnotetext{
${ }^{23}$ Note that this stylized calculation abstracts from state capital gains tax rates as well as other tax interactions.
} 